\title{
Unplanned Pregnancy and Its Associated Factors
}

\author{
Muslimah Yusof ${ }^{1}$, Azah Abdul Samad ${ }^{2}$, Maisarah Omar ${ }^{1} \&$ Noor Ani Ahmad ${ }^{1}$ \\ ${ }^{1}$ Institute for Public Health, National Institutes of Health, Ministry of Health Malaysia, Jalan Bangsar, Kuala \\ Lumpur, Malaysia \\ ${ }^{2}$ Shah Alam Section 7 Health Clinic, Shah Alam, Selangor, Malaysia \\ Correspondence: Muslimah Yusof, Institute for Public Health, National Institutes of Health, Ministry of Health \\ Malaysia, Jalan Bangsar, 50590 Kuala Lumpur, Malaysia. E-mail: muslimah_yusof@moh.gov.my
}

\author{
Received: February, 25, 2018 Accepted: June 5, 2018 Online Published: July 25, 2018 \\ doi:10.5539/gjhs.v10n8p132 URL: https://doi.org/10.5539/gjhs.v10n8p132
}

\begin{abstract}
Introduction: Unplanned pregnancy is a major public health concern globally. Numerous studies found various factors that can predict or determine unplanned pregnancy. However, there were no studies that reported this problem in Malaysia. The objective of this study is to determine the prevalence of unplanned pregnancy in Malaysia and the associated factors.

Methods: This nationwide cross-sectional study targeted to women at postpartum period at government primary health care clinics throughout Malaysia. Structured questionnaire with face-to-face interview was used for data collection. The factors studied included mothers' age, husband's age, ethnicity, religion, marital status, education, occupation, household income, polygamous marriage, family support, contraception used, and disagreement of husband on contraception, smoking and alcohol consumption. History of emotional, physical and sexual intimate partner violence (IPV) were also studied.

Results: A total of 5727 Malaysian postpartum mothers were involved in this survey. The prevalence of unplanned pregnancy was $42.9 \%(95 \%$ CI: 38.6, 47.4). The multivariate logistic regression revealed that older mothers aged 45-49 years old (aOR: 8.010; 95\%CI: 1.909, 33.013) and Muslim mothers (aOR: 2.465; 95\%CI: 1.432-4.241) were significantly associated with unplanned pregnancy. In terms of household income, mothers with less than RM1000 per month were 1.712 (95\% CI: 1.080, 2.713) times more likely to have unplanned pregnancy. The other significant associated factor was history of emotional intimate partner violence; aOR [1.720 (95\% CI: 1.011, 2.925)].

Conclusions: Unplanned pregnancies were observed to be higher among older Muslim women from low income family. A possibility of unmet need for family planning should be considered and appropriate intervention strategies planned for these at-risk population.
\end{abstract}

Keywords: unplanned pregnancy, unwanted pregnancy, prenatal care, contraception, Malaysia

\section{Introduction}

An unplanned pregnancy is a pregnancy that is reported to have either unwanted (that is, the pregnancy occurred when no children, or no more children, were desired) or mistimed (that is the pregnancy occurred earlier than desired) (CDC, 2015; Yunikkerem, Ay, \& Piro, 2013; Santelli et al., 2003; Singh, Darroch, Ashford, \& Vlassoff, 2009). In contrast, intended pregnancies are when they happened at the 'right time' or later than desired (because of infertility or difficulties in conceiving).

Unplanned pregnancy is a major public health concern in developed and developing countries because of its adverse health outcomes among women and children. Globally many pregnancies are still unplanned. In the United States, the proportion of pregnancies that were unplanned increased slightly between 2001 and 2008 (from $48 \%$ to $51 \%$ ), but, by 2011, it decreased to $45 \%$ (Finer \& Zolna, 2016; Finer \& Zolna, 2014).

According to a global report 2008, in all pregnancies 208.2 million, there was $41 \%$ unplanned pregnancy. Latin America/Caribbean showed 58\% unplanned pregnancies, North America (48\%), Europe (44\%) followed by Africa (39\%). Asia showed 37\% unplanned pregnancy of all pregnancies 118.8 million (Singh, Sedgh, \& Hussain, 2010; Sedgh, Singh \& Hussain, 2014). Finding from the third National survey of sexual attitudes and life styles in Britain showed $16.2 \%$ of pregnancies with known outcome in the past year was unplanned (Wellings, et al., 2013; WHO, 2008). 
Various reasons for unplanned pregnancies have been identified, which include non-use of contraceptive methods and contraceptive method failure. Non-use of contraceptive methods is one of the important reasons for unplanned pregnancy, which is mainly due to the high unmet need for contraceptives. Contraceptive method failure incorporates both users and technological faults (Kost, Singh, Vaughan, Trussell, \& Bankole, 2008).

Numerous studies found various factors that can predict or determine unplanned pregnancy. However, there were no studies that report this problem in Malaysia. Thus, the objective of this study is to determine the prevalence of unplanned pregnancy in Malaysia and the associated factors.

\section{Material and Methods}

This is a nationwide clinic-based cross-sectional study of women with infants in the perinatal period (6-16 weeks) conducted at the Maternal and Child Health Unit at government primary care clinics throughout Malaysia. To ensure national representativeness, cluster sampling design was employed with health clinics considered as cluster. Health clinics within states were randomly selected and eligible mothers within the health clinics were considered as unit of analysis. Detail methodology has been described elsewhere by Ahmad et al. (2018).

The inclusion criteria for this study were mothers who delivered a child within 6 to 16 weeks of recruitment, who consented to be involved in the study. Only respondents of the legal age of 18 years or above were invited to join this survey. The exclusion criteria were those under the legal consenting age.

Data was collected using a combination of both face-to-face interview. Responses were captured using tablets with built-in quality control to minimize errors and was uploaded to the server in the institute after the quality check done. Data collection was done within the clinic vicinity. Information sheet and consent forms were made available to every respondent.

\subsection{Variable Definition}

In this study unplanned pregnancy was defined as responded 'yes' to the question "Was your last pregnancy planned or unplanned?" was used to categorise the pregnancy as planned or unplanned.

Ethnicity was classified based on the major ethnic groups in Malaysia: Malays, Malaysian Chinese, and Malaysian Indian. Sarawakian and Sabahan are indigenous groups from local Sarawakians and Sabahans and Orang Asal, and 'Others" was mostly composed of foreigners, immigrants, both legal and illegal, residing in Malaysia. The religion was based on the main religious in Malaysia, Islam, Buddhism, Hinduism, Christianity, Other religion and No religion.

The education levels were categorized based on the Malaysian education system. Respondents were considered to have no formal education/primary education if they had not attended any formal schooling or had only completed up to 6 years of primary school. Those who had completed 11 years of formal schooling were defined as having completed secondary education while respondents with diplomas or higher qualifications were considered as having completed tertiary education. Household income was categories by locally accepted group for household income, calculated based on the pooled income of family members and categorized into six group.

Family support during confinement was defined as an answer of 'yes' to the questions "Did you observe a confinement period after your last child birth" and "When you need help or have a problem, can you usually count on family member for support?" Polygamous marriage and contraception use was defined as an answer of 'yes' to the questions "Are you in a polygamous marriage?" and "Do you ever use any methods to avoid pregnancy?"

Intimate partner violence (IPV) was defined as a single or repeated experience of physical and/or sexual violence. IPV assessed based on the questionnaire used in the WHO Multicounty Study on Women's Health and Life Events (WHO, 2005). Physical violence was defined as positive responses to a history of being slapped, pushed, beaten, kicked, choked or threatened with a weapon, and sexual violence was defined as a positive response for any history of sexual coercion, sex out of fear or forced to engage in a degrading sexual act. Emotional violence was defined as a positive response ever having been insulted, publicly humiliated, intimidated or threatened or had a partner who threatened to hurt the respondent herself or someone she cared about (Ahmad NA, et al., 2018).

\subsection{Statistical Analysis}

SPSS version 21 was used for data analysis. Descriptive analysis was performed to study the distribution of unplanned pregnancy in pregnant women in Malaysia. The bivariate analysis was done looking for association between an independent variable and unplanned pregnancy. Finally, all the variables were included in the multivariate logistic regression model. The findings were presented as adjusted odd ratio with $95 \%$ confident interval and a $\mathrm{p}$ value less than 0.05 was considered significant. 


\section{Results}

\subsection{Socio-Demographic Profile of Sample}

A total of 5727 Malaysian postpartum mothers were involved in this survey. Among age groups, the highest percentage was from those aged 25-29 years old (33.0\%), while for the respondents' husband's age was from 30-34 years old (32.3\%). More than half of them were Malay (63.3\%), Islam (74.2\%), mothers with secondary education $(60.0 \%)$, not working mothers (53.6\%). By household income, the highest percentage was from RM5000 and above group. Only $1.3 \%$ of them were not married or had no current partner. The details of socio-demographic characteristics of the respondents are shown in Table 1.

Table 1. Socio-demographic characteristics of the respondents $(\mathrm{n}=5727)$

\begin{tabular}{|c|c|c|}
\hline & Frequency & $\%$ \\
\hline \multicolumn{3}{|l|}{ Respondent's age group } \\
\hline $18-19$ years old & 140 & 2.4 \\
\hline 20-24 years old & 903 & 13.9 \\
\hline 25-29 years old & 1842 & 33.0 \\
\hline 30-34 years old & 1749 & 31.5 \\
\hline 35-39 years old & 866 & 15.4 \\
\hline 40-44 years old & 207 & 3.6 \\
\hline 45-49 years old & 20 & 0.2 \\
\hline \multicolumn{3}{|l|}{ Husband's age } \\
\hline $15-19$ years old & 32 & 0.5 \\
\hline 20-24 years old & 368 & 6.0 \\
\hline 25-29 years old & 1429 & 23.9 \\
\hline 30-34 years old & 1794 & 32.3 \\
\hline 35-39 years old & 1098 & 21.4 \\
\hline 40-44 years old & 841 & 10.6 \\
\hline 45-49 years old & 204 & 3.4 \\
\hline 50 years old and above & 108 & 1.8 \\
\hline \multicolumn{3}{|l|}{ Ethnicity } \\
\hline Malay & 3889 & 63.3 \\
\hline Chinese & 549 & 12.8 \\
\hline Indians & 262 & 4.1 \\
\hline Sarawakian & 253 & 5.8 \\
\hline Sabahan & 471 & 9.0 \\
\hline Orang Asal & 29 & 0.6 \\
\hline Others & 274 & 4.3 \\
\hline \multicolumn{3}{|l|}{ Religion } \\
\hline Islam & 4501 & 74.2 \\
\hline Buddha & 521 & 12.1 \\
\hline Hindu & 237 & 3.7 \\
\hline Christian & 414 & 8.3 \\
\hline Other religion & 9 & 0.3 \\
\hline No religion & 45 & 1.3 \\
\hline
\end{tabular}




\section{Education level}

No formal/primary education

$$
382
$$

3300

2045

Tertiary education

\section{Occupation}

Working

Not working

\section{Marital status}

Married/have partner

Not married/no current partner

\section{Household income}

Less than RM1000

RM1000-1999

RM2000-2999

RM3000-3999

RM4000-4999

RM5000 and above

\section{Family Support}

Yes

No

No other family member

\section{Polygamous marriage}

Yes

No

Contraception use

Yes

No

Disagreement of husband on contraception

$\begin{array}{ll}\text { Yes } & 632 \\ \text { No } & 5094\end{array}$

\section{Alcohol drink}

Yes

No

Uncertain

Smoking

Yes

No

Uncertain

History of Emotional IPV

Yes

No
2807

2919

46.4

53.6

5654

98.7

73

1.3

\section{3}

11.2

1282

23.1

1044

18.2

894

14.4

532

8.3

1462

24.7

5229

90.2

464

8.8

34

1.0

\section{6}

1.4

5560

98.6

3011

55.3

2710

44.7

\section{2}

11.2

5094

88.8

21

0.4

5634

98.6

70

1.4

28

5666

0.5

99.1

33

0.4

5523

3.8

198

96.2 


\begin{tabular}{lll}
\hline History of Physical IPV & & \\
Yes & 123 & 97.5 \\
No & 5592 & 2.5 \\
\hline History of Sexual IPV & & \\
Yes & 65 & 98.8 \\
No & 5659 & 1.2 \\
\hline
\end{tabular}

\subsection{Prevalence of Unplanned Pregnancy and Associated Factors}

The prevalence of unplanned pregnancy was $42.9 \%$ (95\% CI: 38.6, 47.4). By age group the prevalence was highest among older mothers aged $45-49$ years old at $79.3 .4 \%$ (95\% CI: 53.7, 92.7) while for husband's age, the highest prevalence was among youngest husband aged $15-19$ years old at $65.5 \%$ (95\% CI: 37.6, 85.7). By ethnicity, Sabahan native showed the highest prevalence of $47.4 \%$ (95\%CI: 36.4, 58.6). Mothers with no formal education or only primary education were found to be more prevalent to unplanned pregnancy with the prevalence of $47.2 \%$ (95\% CI: 40.5, 54.0). According to household income, the highest prevalence was among less than RM1000 group at 49.1\% (95\% CI: 41.2, 57.1) (Table 2). Unmarried/no current partner mothers were noted to have significantly higher prevalence at $84.9 \%$ (95\% CI: $70.9,92.9)$ as compared to married mothers $(42.4 \%$; $95 \%$ CI: $38.0,46.9)$. Mothers in polygamous marriage were found to have higher prevalence at $44.0 \%$ (95\% CI: $27.8,61.6)$ as compared to monogamous marriage at $42.5 \%$ (95\% CI: $38.1,47.0)$.

Table 2. Prevalence of unplanned pregnancy by socio-demographic characteristics $(n=5727)$

\begin{tabular}{|c|c|c|c|c|}
\hline \multirow{2}{*}{ Variable } & \multicolumn{3}{|c|}{ Unplanned pregnancy } & \multirow{2}{*}{ P value * } \\
\hline & Frequency, n & $\%$ & $95 \% \mathrm{CI}$ & \\
\hline Respondent's age group & & & & $<0.001$ \\
\hline 18-19 years old & 76 & 48.7 & $33.0,64.7$ & \\
\hline 20-24 years old & 407 & 44.1 & 37.4. 51.0 & \\
\hline 25-29 years old & 772 & 41.3 & $36.4,46.3$ & \\
\hline 30-34 years old & 667 & 38.8 & $34.2,43.7$ & \\
\hline 35-39 years old & 394 & 47.7 & $41.4,54.0$ & \\
\hline 40-44 years old & 119 & 63.4 & $54.3,71.7$ & \\
\hline $45-49$ years old & 16 & 79.3 & $53.7,92.7$ & \\
\hline Husband's age & & & & 0.006 \\
\hline $15-19$ years old & 21 & 65.5 & $37.6,85.7$ & \\
\hline 20-24 years old & 176 & 47.4 & $37.0,58.0$ & \\
\hline 25-29 years old & 598 & 40.3 & $34.5,46.2$ & \\
\hline 30-34 years old & 709 & 40.7 & $36.0,45.6$ & \\
\hline 35-39 years old & 424 & 38.9 & $33.2,44.8$ & \\
\hline 40-44 years old & 253 & 48.5 & $41.2,55.8$ & \\
\hline 45-49 years old & 117 & 53.8 & $43.7,63.6$ & \\
\hline 50 years old and above & 56 & 56.0 & $42.4,68.8$ & \\
\hline Ethnicity & & & & 0.232 \\
\hline Malay & 1719 & 44.9 & $40.5,49.5$ & \\
\hline Chinese & 194 & 36.3 & $27.2,47.1$ & \\
\hline Indian & 123 & 44.4 & $32.1,57.5$ & \\
\hline Sarawakian & 95 & 29.3 & $14.8,49.6$ & \\
\hline
\end{tabular}




\begin{tabular}{lllll}
\hline Sabahan & 198 & 47.4 & $36.4,58.6$ & \\
Orang Asal & 15 & 44.2 & $19.3,72.4$ & \\
Others & 109 & 39.9 & $29.7,51.0$ & \\
\hline Religion & & & & 0.064 \\
Islam & 1987 & 45.5 & $41.3,49.8$ & \\
Buddha & 187 & 36.5 & $27.6,46.5$ & \\
Hindu & 113 & 43.8 & $29.3,59.4$ & \\
Christian & 144 & 30.3 & $19.1,44.4$ & \\
Other religion & 4 & 48.3 & $13.4,85.0$ & \\
$\quad$ No religion & 18 & 33.2 & $19.2,51.0$ & \\
\hline Education level & & & & 0.438 \\
$\quad$ No formal/primary education & 172 & 47.2 & $40.5,54.0$ & \\
Secondary education & 1445 & 43.0 & $38.2,48.0$ & \\
Tertiary education & 836 & 41.8 & $36.4,47.5$ & \\
\hline Occupation & & & & 0.330 \\
$\quad$ Working & 1144 & 41.5 & $36.7,46.5$ & \\
$\quad$ Not working & 1309 & 44.2 & $38.9,49.6$ & \\
\hline Marital status & & & & $<0.001$ \\
$\quad$ Married/have partner & 2396 & 42.4 & $38.0,46.9$ & \\
$\quad$ Not married/no current partner & 57 & 84.9 & $70.9,92.9$ & \\
\hline
\end{tabular}

* Rao-scott adjusted chi-square statistic. Significance is based on the adjusted $\mathrm{F}$ and its degrees of freedom.

\subsection{Maternal Factors}

Mothers with no contraception use were noted with a higher prevalence of unplanned pregnancy at $45.8 \%$ (95\% CI: 40.4, 51.3). Alcohol drink and smoking during pregnancy showed significantly higher prevalence of unplanned pregnancy with the prevalence of $56.3 \%$ (95\% CI: $26.3,82.3)$ and $73.7 \%(95 \%$ CI: $46.2,90.2)$ respectively.

\subsection{Support System}

With regards to family support, mothers with no other family member showed the highest prevalence of unplanned pregnancy at $65.1 \%(95 \% \mathrm{CI} ; 37.2,85.5)$. Alcohol drink and smoking during pregnancy showed significantly higher prevalence of unplanned pregnancy with the prevalence of $56.3 \%$ (95\% CI: $26.3,82.3)$ and $73.7 \%$ (95\% CI: $46.2,90.2)$ respectively. In term of intimate partner violence, mothers with history of emotional, physical and sexual prevalence were revealed to have higher prevalence at $61.0 \%$ (95\% CI: $45.2,74.8,), 60.5 \%(95 \% \mathrm{CI}: 41.5$, $76.9)$ and $76.2 \%$ (95\%CI: 58.3, 88.0) accordingly (Table 3). 
Table 3. Factor associated with unplanned pregnancy $(n=5727)$

\begin{tabular}{|c|c|c|c|c|}
\hline \multirow{2}{*}{ Variables } & \multirow{2}{*}{ Odd ratio, $O R$} & \multirow{2}{*}{ CI $(95 \%)$} & \multicolumn{2}{|c|}{ Adjusted odds ratio, aOR } \\
\hline & & & aOR & CI $(95 \%)$ \\
\hline \multicolumn{5}{|c|}{ Family Support } \\
\hline Yes & - & & - & \\
\hline No & 1.299 & $0.74,1.733$ & 1.150 & $0.856,1.545$ \\
\hline $\begin{array}{l}\text { No other } \\
\text { member }\end{array}$ & 2.567 & $0.847,7.779$ & 2.867 & $0.751,0.944$ \\
\hline \multicolumn{5}{|c|}{ History of Emotional IPV } \\
\hline Yes & 2.142 & $1.150,3.987$ & 1.720 & $1.011,2.925$ \\
\hline No & - & & - & \\
\hline \multicolumn{5}{|c|}{ History of Physical IPV } \\
\hline Yes & 2.078 & $0.992,4.350$ & 1.329 & $0.728,2.429$ \\
\hline No & - & & - & \\
\hline \multicolumn{5}{|c|}{ History of Sexual IPV } \\
\hline Yes & 4.318 & $1.828,10.199$ & 2.746 & $0.842,8.948$ \\
\hline No & - & & - & \\
\hline
\end{tabular}

\subsection{Predictors of Unplanned Pregnancy}

Table 4 shows the multivariate logistic regression revealed that elder mothers aged 45-49 years old (aOR: 8.010; 95\% CI: $1.909,33.013$ ) and Muslim mothers (aOR: 2.465 ; 95\%CI: 1.432-4.241) were significantly associated with unplanned pregnancy. In term of household income, mothers in the group of less than RM1000 per month were $1.712(95 \%$ CI: 1.080, 2.713) times more likely to have an unplanned pregnancy. The other associated factor was history of emotional intimate partner violence with AOR of $1.720(95 \%$ CI: $1.011,2.925)$.

Table 4. Multivariate analysis of the factors associated with unplanned pregnancy $(n=5727)$

\begin{tabular}{|c|c|c|c|c|}
\hline \multirow{2}{*}{ Variables } & \multirow{2}{*}{ Odd ratio, $O R$} & \multirow{2}{*}{ CI (95\%) } & \multicolumn{2}{|c|}{ Adjusted odds ratio, aOR } \\
\hline & & & aOR & CI $(95 \%)$ \\
\hline \multicolumn{5}{|c|}{ Respondent's age group } \\
\hline 18-19 years old & 1.352 & $0.743,2.458$ & 1.279 & $0.753,2.174$ \\
\hline 20-24 years old & 1.121 & $0.900,1.397$ & 0.988 & $0.775,1.267$ \\
\hline $25-29$ years old & $\mathrm{R}$ & & $\mathrm{R}$ & \\
\hline $30-34$ years old & 0.903 & $0.768,1.061$ & 1.000 & $0.805,1.244$ \\
\hline $35-39$ years old & 1.296 & $1.018,1.648$ & 1.493 & $1.098,2.030$ \\
\hline $40-44$ years old & 2.466 & $1.590,3.822$ & 2.731 & $1.586,4.702$ \\
\hline $45-49$ years old & 5.453 & $1.672,17.786$ & 8.010 & $1.909,33.013$ \\
\hline \multicolumn{5}{|l|}{ Religion } \\
\hline Islam & 1.925 & $1.036,3.577$ & 2.465 & $1.432,4.241$ \\
\hline Buddha & 1.326 & $0.701,2.509$ & 1.310 & $0.581,2.953$ \\
\hline Hindu & 1.794 & $0.700,4.599$ & 0.990 & $0.158,2.953$ \\
\hline Christian & $\mathrm{R}$ & & $\mathrm{R}$ & \\
\hline Other religion & 2.151 & $0.407,11.360$ & 2.112 & $0.560,7.961$ \\
\hline No religion & 1.145 & $0.568,2.308$ & 1.360 & $0.483,3.832$ \\
\hline
\end{tabular}




\begin{tabular}{lcccc}
\hline Household income & & & & \\
Less than RM1000 & 1.654 & $1.115,2.455$ & 1.712 & $1.080,2.713$ \\
RM1000-1999 & 1.370 & $0.993,1.889$ & 1.497 & $1.028,2.179$ \\
RM2000-2999 & 1.377 & $1.069,1.773$ & 1.506 & $1.112,2.040$ \\
RM3000-3999 & 1.295 & $0.980,1.712$ & 1.378 & $1.042,1.822$ \\
RM4000-4999 & 1.404 & $1.021,1.928$ & 1.430 & $1.046,1.957$ \\
RM5000 and above & $\mathrm{R}$ & & $\mathrm{R}$ & \\
\hline
\end{tabular}

Control for husband's age, ethnicity, education level, occupation, marital status, polygamous marriage, contraception use, disagreement of husband on contraception, alcohol drink, and smoking.

$\mathrm{R}=$ reference.

\section{Discussion}

There are many factors associated with unplanned pregnancies and studies have reported different determinants and different predictors on this issue. These factors can be divided into sociodemographic and socioeconomic which included couple's age, their socioeconomic status, education, occupational status and residential area. The associated fertility related factors included mother's age at the time of marriage, gravidity and parity. Other related factors included the use of contraceptives, substance abuse and intimate partner violence.

Our findings revealed, $42.9 \%$ of the pregnancies were unplanned. The analysis was focused on the last pregnancy with the intention of minimizing recall bias. The current rate is lower than findings in the United States, a developed country, $49 \%$ of pregnancies were unplanned (CDC, 2015) but consistent with reports from other studies which reported average prevalence to be $35 \%$ ranging from $13 \%$ to $82 \%$ (Ali, Tikmani, \& Qidwai, 2016; Habte, Teklu, Melese \& Magafu, 2013). There is no data on unplanned pregnancies in Malaysia however various data estimates $25 \%$ of unplanned pregnancies in Malaysia (Helen, 2015).

\subsection{Maternal Age}

Our study showed that the prevalence of unplanned pregnancies was highest among the older mothers aged 45- 49 years old at $79.3 \%$. Studies found that women's age was the best predictor of pregnancy intention (Ali, Tikmani, \& Qidwai, 2016). In a systematic review study, age was positively related to unplanned pregnancy and more studies found older women were more likely to experience unplanned pregnancy compared to younger women (Ali, Tikmani, \& Qidwai, 2016). On the contrary, studies from Nigeria, Vietnam and Bangladesh have found that women usually experienced unplanned pregnancy at extreme childbearing age groups, both the younger and older age groups (Okonofua, Odimegwu, Ajabor, Daru, \& Johnson, 1999; Cu Li, Magnani, Rice, Speizer, \& Bertrand, 2004; Rahman, 2012; Kamal \& Islam, 2011). Older women were found to prefer natural contraceptive methods compared to modern contraception which resulted in contraceptive failure. (NIPORT, 2009).

\subsection{Education Level}

Mothers with no formal education or only received a primary education were found to be more prevalent to an unplanned pregnancy with the prevalence of $47.2 \%$ in this study. Women's education is an important factor in explaining the fertility and fertility behavior of women. Many studies concluded a significant relationship between educational level and the likelihood of unplanned pregnancies (Ali, Tikmani, \& Qidwai, 2016). Our finding is consistent with other studies which showed that women with primary or less education were more likely to experience unplanned pregnancy (Habte, Teklu, Melese \& Magafu, 2013; Tebekaw, Aemro, \& Teller, 2014; Islam \& Rashid, 2005; Takahashi et al., 2012). As the educational level increases the prevalence of unplanned pregnancies would decrease. Literate women have more knowledge on their rights and responsibilities to participate and hence can plan for their own reproductive and sexual health (Habib et al., 2017).

\subsection{Socioeconomic Status}

A systematic review found women with high economic status were less likely to experience unplanned pregnancy (Ali, Tikmani, \& Qidwai, 2016). Significant relationships were found between economic factors and pregnancy intention (Okonofua, Odimegwu, Ajabor, Daru, \& Johnson, 1999; Adhikari, Soonthorndhada, \& Prasartkul, 2009). Similar to our findings, mothers in the group of less than RM1000 per month were $71 \%$ higher have an unplanned pregnancy. The financial constraint was the most important factor determining the intention of pregnancy. Generally, women with high economic status were less likely to experience an unplanned pregnancy. These 
findings suggest that women from poor income group were less likely to afford family planning services or less likely to have access to the family planning services (NIPORT, 2009).

\subsection{Socio Cultural, Religion and Women's Autonomy}

In our study Muslim mothers were found to be significantly associated with unplanned pregnancy. This is similar to a study done in Bangladesh, where Muslim women, as compared to non-Muslim, had a higher incidence of unplanned pregnancy (30.9\% vs. 20.3\%) (Cu Li, Magnani, Rice, Speizer, \& Bertrand, 2004). Malaysia, being a Muslim country, the majority (61\%) of our population is a Muslim (DOSM, 2010). Our findings could be related to the Islamic institution who put husbands as the one in charge of the family and any other decision making pertaining family matters (Omran, 1992).

Social norms also limit women's freedom to make important decisions as they are dependent on their male partners for their daily living (Ali, Ali, \& Suhail, 2016; Rahman, 2012). In developing countries, men are usually considered as the main decision maker especially in the male dominant societies. The men will decide on the health seeking behavior pattern of the family members including the use of contraception. (Ali, Ali, \& Suhail, 2016; Rahman, 2012). Women who have discussed the intention of taking family planning showed less prevalence of unplanned pregnancy compared to women whose have never discussed it with the husbands $(28.4 \%$ vs. $31.1 \%)$ (Kamal \& Islam, 2011). Findings relate that Muslim women are less likely to use modern methods due to their traditional beliefs and cultural norms and older women are more reluctant to use modern methods as compared to their younger counterparts, resulting in higher risk of unplanned pregnancy among the former (NIPORT, 2009).

A report had shown contraceptive prevalence rate in Malaysia for all available method is $55 \%$ and for modern methods is $32 \%$. This is much lower compared to global, $63 \%$ and lesser than neighbouring countries, Singapore $55.1 \%$ and Thailand $77.5 \%$. (Najimudeen \& Sachchithanantham, 2014). Husband's objection (8\% - 12.6\%) contributed for the reasons for not using contraceptive methods. (Najimudeen \& Sachchithanantham, 2014).

\subsection{Emotional Intimate Violence}

The other associated factor that was significant in our study was history of emotional intimate partner violence. In a study done by Stella Martin et al, similar findings were noted. Emotional intimate partner violence was associated with unplanned pregnancy aOR $=2.5,95 \% \mathrm{CI}+1.5-4.3$ ) (Martin-de-las-Heras, Velasco, de Dios Luna, \& Martin, 2015).

\section{Strengths and Limitations}

The main strength of our study is the large nationally represented data with a robust method. The response rate was good $(85.9 \%)$ and various socio-demographic and socio-cultural factors were examined.

Nevertheless, our findings have several limitations. There was no data on the locality of the samples. Accessibility to health services was not explored. Details of the unintended pregnancy should be probed further as it could be 'mistimed' instead of unintended.

\section{Conclusion and Policy Implication}

This study examined the prevalence and socioeconomic correlates of unplanned pregnancy among Malaysian women who attended the government primary health care clinics during the perinatal period. Findings revealed overall, $42.9 \%$ of the most recent pregnancies were unplanned. Significant predictors of unplanned pregnancy found were elder mothers aged 45-49 years old, Muslim mothers, mothers of lower household income and mothers with a history of emotional intimate partner violence. Studies should be conducted to find reasons for the unplanned pregnancies. The relationship between education, health economic status and women's sexual and reproductive health practices should be studied. The positive association between unplanned pregnancies among Muslim women reflects an association with the religious and cultural belief. Therefore, there is a special concern to see the effect of religion and culture on contraceptive practices. Family planning services are offered free of charge by government health facilities in Malaysia. Although services are free, contraception usage rates are still low. A study should be conducted to identify the unmet needs of family planning in Malaysia.

\section{Acknowledgements}

We would like to thank the Director General of Health Malaysia for his permission to publish this article. We also thank the Deputy Director General of Health (Research and Technical Support) for continuous support and guidance. Our gratitude goes to the Asia Pacific International Research and Education (ASPIRE) Network for their contribution to the concept of this study and to everyone involved in making this study a success. 


\section{Competing Interests Statement}

All authors declare no competing interest.

\section{References}

Adhikari, R., Soonthorndhada, K., \& Prasartkul, P. (2009). Correlates of unintended pregnancy among currently pregnant married women in Nepal. BMC International Health and Human Rights, 9(1), 1. https://doi.org/10.1186/1472-698X-9-17

Ahmad, N. A., Silim, U. A., Rosman, A., Mohamad, M., Chan, Y. Y., Yusof, M., ... Aris, T. (2018). Postnatal depression and intimate partner violence: a nationwide clinic based cross-sectional study in Malaysia. $B M J$ Open, 8, e020649. https://doi.org/10.1136/bmjopen-2017-020649

Ali, S., Ali, S. A., \& Suhail, N. (2016). Determinants of Unintended Pregnancy among woman of Reproductive Age in developing countries: A Narrative Review. Journal of Midwifery and Reproductive Health, 4(1), 513-21.

Ali, S. A., Tikmani, S. S., \& Qidwai, W. (2016). Prevalence and determinants of Unintended Pregnancy: Systematic Review. Middle East Journal of Family Medicine, 14(6), 37-46. https://doi.org/10.5742/MEWFM.2016.92806

Centers for Disease Control (CDC): Unintended Pregnancy Prevention: Home. (2015). Retrieved November 20, 2017 from http://www.cdc.gov/reproductivehealth/unintendedpregnancy.

$\mathrm{Cu}$ Le, L., Magnani, R., Rice, J., Speizer, I., \& Bertrand, W. (2004). Reassessing the level of unintended pregnancy and its correlates in Vietnam. Studies in Family Planning, 35(1), 15-26. https://doi.org/10.1111/j.1728-4465.2004.00002.x

Department of Statistics Malaysia (DOSM) Population Distribution and Basic Demographic Characteristic Report 2010 (Updated 2011).

Finer, L. B., \& Zolna, M. R. (2016). Declines in unintended pregnancy in the United States, 2008-2011. New England Journal of Medicine, 374(9), 843-852. https://doi.org/10.1056/NEJMsa1506575

Finer, L. B., \& Zolna, M. R. (2014). Shifts in intended and unintended pregnancies in the United States, 20012008. American Journal of Public Health, 104(S1), S44-S48. https://doi.org/10.2105/AJPH.2013.301416

Habib, A., Greenow, C., Nausheen, S., Soofi, S., Sajid, M., Bhutta, Z., \& Black, K. (2017). Prevalence and determinants of unintended pregnancies amongst women attending antenatal clinics in Pakistan. BMC Pregnancy and Childbirth, 17(156), 1-10. https://doi.org/10.1186/s12884-017-1339-z

Habte, D., Teklu, S., Melese, T., \& Magafu, M. G. M. D. (2013) Correlates of Unintended Pregnancy in Ethiopia: Results from a National Survey. PLoS ONE, 8(12), e82987. https://doi.org/10.1371/journal.pone.0082987

Helen. (2015). 25\% of pregnancies in Malaysia unplanned. The Borneo Post.

Kamal, M., \& Islam, A. (2011). Prevalence and socioeconomic correlates of unintended pregnancy among women in rural Bangladesh. Salud Publica Mex, 53, 108-115. https://doi.org/10.1590/S0036-36342011000200003

Kost, K., Singh, S., Vaughan, B., Trussell, J., \& Bankole, A. (2008). Estimates of contraceptive failure from the 2002 National Survey of Family Growth. Contraception, 77(1), 10-21. https://doi.org/10.1016/j.contraception.2007.09.013

Martin-de-las-Heras, S., Velasco, C., de Dios Luna, J., \& Martin, A. (2015). Unintended pregnancy and intimate partner violence around pregnancy in a population-based study. Women and Birth, 28(2), 101-105. https://doi.org/10.1016/j.wombi.2015.01.003

Najimudeen, M., \& Sachchithanantham, K. (2014). An insight into low contraceptive prevalence in Malaysia and its probable consequences. Int $J$ Reprod Contracept Obstet Gynecol, 3(3), 493-496. https://doi.org/10.5455/2320-1770.ijrcog20140943

National Institute of Population Research and Training [NIPORT]. (2009). Mitra and Associates, and Macro International. 2009. Bangladesh Demographic and Health Survey 2007. Dhaka, Bangladesh and Calverton, Maryland, USA: National Institute of Population Research and Training, Mitra and Associates, and Macro International.

Okonofua, F. E., Odimegwu, C., Ajabor, H., Daru, P. H., \& Johnson, A. (1999). Assessing the prevalence and determinants of unwanted pregnancy and induced abortion in Nigeria. Studies in Family Planning, 30(1), 
67-77. https://doi.org/10.1111/j.1728-4465.1999.00067.x

Omran, A. R. (1992). Family Planning in the Legacy of Islam (London: Routledge).

Rahman, M. (2012). Women's autonomy and unintended pregnancy among currently pregnant women in Bangladesh. Maternal and Child Health Journal, 16(6), 1206-1214. https://doi.org/10.1007/s10995-011-0897-3

Santelli, J., Rochat, R., Hatfield-Timaichy, K., Gilbert, B. C., Curti,s K., Cabral, ... Schieve, L. (2003). The measurement and meaning of unintended pregnancy. Perspectives on Sexual and Reproductive Health, 35(2), 94-101. https://doi.org/10.1363/3509403

Sedgh, G., Singh, S., \& Hussain, R. (2014). Intended and Unintended Pregnancies Worldwide in 2012 and Recent Trends. Stud Fam Plann, 45(3), 301-314. https://doi.org/10.1111/j.1728-4465.2014.00393.x

Singh, S., Darroch, J.E., Ashford, L. S. \& Vlassoff, M. (2009). Guttmacher Institute and United Nations Population Fund. Retrieved November 20, 2017 from www.guttmacher.org/ pubs/AddingItUp2009.pdf.

Singh, S., Sedgh, G., \& Hussain, R. (2010). Unintended pregnancy: worldwide levels, trends, and outcomes. Stud Fam Plann, 41(4), 241-50. https://doi.org/10.1111/j.1728-4465.2010.00250.x

Takahashi, S., Tsuchiya, K. J., Matsumoto, K., Suzuki, K., Mori N., \& Takei, N. (2012). Psychosocial determinants of mistimed and unwanted pregnancy: the Hamamatsu Birth Cohort (HBC) study. Maternal and child health Journal, 16(5), 947-55. https://doi.org/10.1007/s10995-011-0881-y

Tebekaw, Y., Aemro, B., \& Teller, C. (2014). Prevalence and determinants of unintended childbirth in Ethiopia. BMC pregnancy and childbirth, 14(1), 1. https://doi.org/10.1186/1471-2393-14-326

Wellings, K., Jones, K. G., Mercer, C. H., Tanton, C., Clifton, S., Datta, J., ... Johnson, A. M. (2013). The prevalence of unplanned pregnancy and associated factors in Britain: findings from the third National Survey of Sexual Attitudes and Lifestyles (Natsal-3). Lancet, 382, 1807-16. https://doi.org/10.1016/S0140-6736(13)62071-1

World Health Organization [WHO]. (2008). Making pregnancy safer. Adolescent pregnancy. Retrieved November 21, 2017 from www.who.int/making_pregnancy_safer/topics/adolescent_pregnancy/en/index.html.

World Health Organization [WHO]. (2005). WHO Multi-country Study on Women's Health and Life Events Questionnaire (version 9.9). WHO multi-country study on women's health and domestic violence against women: initial results on prevalence, health outcomes and women's responses. Geneva: Switzerland, 2005.

Yanikkerem, E., Ay, S., \& Piro, N. (2013). Planned and unplanned pregnancy: Effects on health practice and depression during pregnancy. J Obstet Gynaecol Res, 39(1), 180-187. https://doi.org/10.1111/j.1447-0756.2012.01958.x

\section{Copyrights}

Copyright for this article is retained by the author(s), with first publication rights granted to the journal.

This is an open-access article distributed under the terms and conditions of the Creative Commons Attribution license (http://creativecommons.org/licenses/by/4.0/). 